\title{
Preface: RILEM technical committee 258-AAA- Development of a performance-based testing concept
}

\author{
Børge Johannes Wigum · Jan Lindgård
}

(C) RILEM 2022

\section{Background}

The International Union of Laboratories and Experts in Construction Materials, Systems and Structures (RILEM), was founded in June 1947, with the aim to promote international scientific cooperation in the area of construction materials and structures. Today, the new meaning of the acronym RILEM (Réunion Internationale des Laboratoires et Experts des Matériaux, systèmes de construction et ouvrages) emphasises its dominant focus on people as well as its worldwide activities, covering 70 countries.

Development and assessment of universal test methods for avoiding deleterious Alkali-Aggregate Reaction (AAR) in concrete have been the focus of consecutive RILEM Technical Committees (TCs) for more than 3 decades. The first TC relating to alkaliaggregate reaction was established in 1988 as TC 106, with Dr Philip Nixon from the Building Research Establishment (BRE) in the UK as the Chairman and Dr Ian Sims from Sandberg, UK (now with RSK Environment Ltd) as the Secretary. The primary objective of the TC was to develop test methods for

B. J. Wigum ( $\square)$

HeidelbergCement, RILEM TC 258-AAA, Oslo,

Northern Europe, Norway

e-mail: BorgeJohannes.Wigum@heidelbergcement.com

J. Lindgård

RILEM TC 258-AAA, SINTEF, Trondheim, Norway

e-mail: jan.lindgard@sintef.no aggregate reactivity that could form the basis for internationally agreed test methods. The subsequent TC 191-ARP, formed in 2000, continued working on aggregate test methods. The 3rd TC 219-ACS was established in 2007. Most of the issues included in the former TC proceeded, but a few new topics were added. One main new activity initialised in this TC was performance testing of concrete, i.e. how safely to use alkali-reactive aggregates. Early in 2014, the TC terminated its activities and concluded the work of the three TCs chaired by Dr Nixon with Dr Sims as the secretary for 25 years.

\section{The current work}

In the 6 year period from 2014 to 2020, the RILEM $\underline{T C}$ 258-AAA developed a performance-based testing concept for the prevention of deleterious AAR in concrete. In total, 5 new recommendations have been developed during this TC, presented in this special issue. The use of the various methods is summarized in an updated Outline Guide (RILEM AAR-0) which is an extended version of the previous edition (2016). The TC has been chaired by Professor Børge Johannes Wigum (HeidelbergCement Northern Europe, Norway/Iceland), whereas the deputy chair has been Dr Jan Lindgård (SINTEF, Norway). The TC comprised four Work Packages (WPs), where the emphasis was also put on implementing the RILEM methods and recommendations as national- and international standards. 
The 1st WP-Performance testing and accelerated testing in the laboratory-was headed by Dr Terje F. Rønning (HeidelbergCement Northern Europe, Norway), and Dr Jan Lindgård (SINTEF, Norway) as the deputy.

The 2nd WP-Performance testing and laboratory vs. field; Exposure sites-was headed by Professor Benoît Fournier (Université Laval, Québec, Canada), and Dr Renaud-Pierre Martin (Université Gustave Eiffel (prev. IFSSTAR), France) as the deputy.

The 3rd WP-Performance testing; Assessment of detailed alkali inventory in concrete, including internal alkali release from aggregates, recycling of alkali and external alkali supply-was headed by Dr Esperanza Menéndez Méndez (Institute of Construction Science, "Eduardo Torroja" (CSIC), Spain), and Dr António Santos Silva (Laboratório Nacional de Engenharia Civil-LNEC, Portugal) as the deputy.

The 4th WP-Verification of alkalis released from aggregates-was headed by Professor Klaartje De Weerdt (Norwegian University of Science and Technology, Norway).

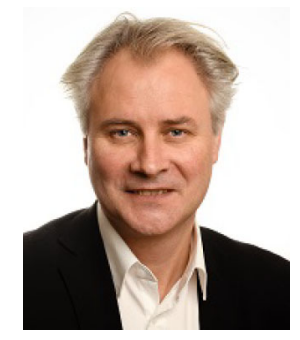

Børge Johannes Wigum

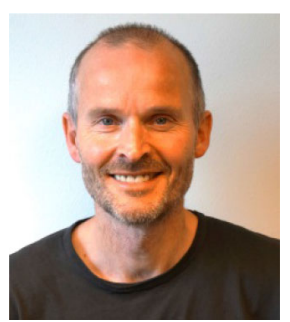

Jan Lindgård

\section{Future follow-ups}

Through more than three decades, and four RILEM TCs, we now have thorough test-methods and procedures for testing the reactivity of various aggregates. We have also developed performance-based test procedures, enabling assessment of new binders and concrete mixes. Expansion measurements from accelerated conditions in laboratories have been compared with results from various outdoor exposure sites, situated within a range of differing climatic conditions. The RILEM recommendations do not include specific critical expansion limits, and it is now a challenge for various countries or regions to establish their own critical limits, correlated to local materials, local climatic conditions and experience. A lot has been invested in the various outdoor exposure sites, and it is of paramount importance that those sites are followed up, with regularly measurements, in the years and decades to come.

A method (AAR-8) to measure the potential alkali release from aggregates has finally been developed. However, it is very important to realise that this accelerated laboratory method must be considered as only an indication of potential alkali release by the aggregates, rather than a quantification that can be used directly in the alkali inventory calculations. To apply the values obtained by the method, it is crucial to verify these numbers by comparing them to what is occurring in real concrete structures or concrete cubes stored at outdoor exposure sites. It is also important to consider if the potential alkali release from aggregates already are to some extent accounted for in the newly presented performance testing concepts.

All these new challenges will be dealt with by a subsequent new RILEM TC (2021-2025); ASR: Risk assessment of concrete mixture designs with alkalisilica reactive (ASR) aggregates. The chairman of this new TC is Professor Jason H. Ideker, from Oregon State University, USA, and deputy-chair is Professor Klaartje De Weerdt, from Norwegian University of Science and Technology. 


\section{Obituary-the late Dr Jonathan G M Wood 1940-2020}

Dr Jonathan G M Wood was an active member of RILEM TC 258-AAA and the later previous TC's relating to AAR. Jonathan was a member of RILEM TC 219-ACS and one of the 3 editors of the RILEM "Guide to Diagnosis and Appraisal of AAR Damage to Concrete in Structures. Part 1 Diagnosis" (AAR 6.1). Jonathan was a specialist on the forensic investigation of structural and materials failures, and on the development of remedial measures and enhanced specifications for steel and concrete bridges, tunnels and buildings. With a BSc from Durham University and a $\mathrm{PhD}$ from the University of Newcastle upon Tyne, both in the UK, he started his career with consultants' Flint \& Neil. He left to join Mott MacDonald (MM) and, when leading their Special Services division in the 1980s, was engaged in worldwide investigations and remedial work on deteriorating bridges, tunnels, and buildings. In the mid1980s, Jonathan acted as an expert witness for the Hospital in the first and possibly only legal case about ASR damage to have taken place in the UK; Dr Ian Sims was an expert for the Defendant, so that the two future TC members met in opposing circumstances! However, over the following years, their paths would frequently cross in pursuit of solutions to ASR, and occasionally they would work together, variously on particular structures, or authoritative publications for The Concrete Society, The British Cement Association, The British Standards Institution and, most notably for Jonathan, The Institution of Structural Engineers (which published a milestone guide on assessing the condition of concrete structures affected by ASR). In 1992, Jonathan left MM and founded Structural Studies and Design Ltd, where, amongst other things, he advised on remedial works to AAR in dams, bridges and buildings. Also in 1992, Jonathan played a major part, with Dr Alan Poole of London University (QMC), in hosting the 9th International Conference on AAR in London; many will recall Jonathan leading a visit to the ASR-affected river bridges in Exeter, South-West England.

Jonathan was a distinctive, worldly and colourful character, who took seriously his responsibilities as a structural engineer, frequently reaching important and new conclusions, ahead of the pack, which he would then energetically advocate to his colleagues and contacts

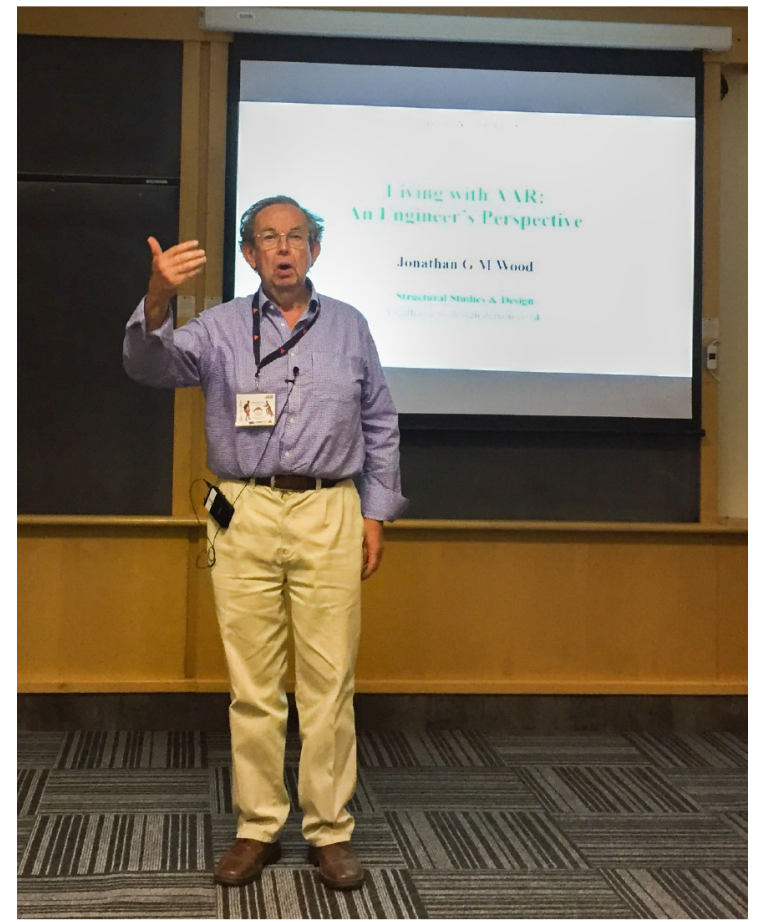

Fig. 1 Presentation at the 5th International Conference on Concrete Repair, Rehabilitation, and Retrofitting (ICCRRR 2018), Cape Town, South Africa, in 2018. (Photo: Børge J. Wigum)

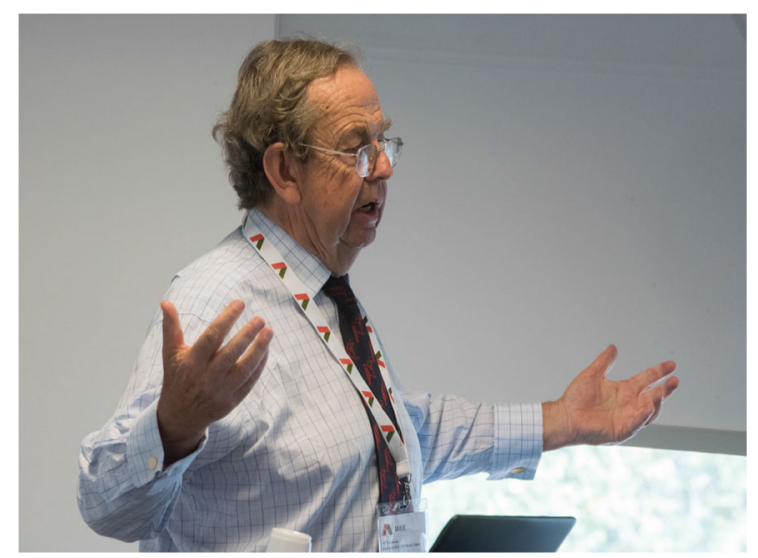

Fig. 2 Presentation at the International Association for Bridge and Structural Engineering-Symposium (IABSE) in Nantes in 2018. (Photo: AFGC)

(Fig. 1). He sadly died in 2020, at the age of 80, just after moving into a new home for his retirement. He leaves his wife Suzie and their three children. Jonathan will be remembered by his structural and civil engineering colleagues for his insight, his skills, his enthusiasm and his ability to solve problems. A true engineer (Fig. 2). 
Publisher's Note Springer Nature remains neutral with regard to jurisdictional claims in published maps and institutional affiliations. 